\title{
Simultaneous bi-pedicled DIEP and TUG flaps to enhance cosmetic outcome in unilateral delayed breast reconstruction: two flaps with three pedicles for one breast
}

\author{
Juan Enrique Berner ${ }^{1,2}$ [D $\cdot$ Ashish Magdum ${ }^{1} \cdot$ Adam Blackburn $^{1}$ \\ Received: 2 October 2019 / Accepted: 20 January 2020 / Published online: 13 February 2020 \\ (C) The Author(s) 2020
}

\begin{abstract}
Autologous breast reconstruction using free tissue transfer allows 'like-for-like' restoration of skin and volume following a mastectomy. Even though the majority of patients will require only one flap to restore their anatomy, occasionally, more than one flap is needed to get the best possible cosmetic outcome. For reconstructing the breast of a slim 49-year-old female patient, a bi-pedicled deep inferior epigastric perforator flap was used to replace the missing skin envelope, in combination with a buried transverse upper gracilis flap for volume restoration. The internal mammary vessels between the second and fourth costal cartilages were used as sole vessel recipient site, by preserving their intercostal perforators. Postoperative recovery was uneventful, and the patient was discharged 2 days after her operation. This case shows how a bi-pedicled DIEP with a TUG flap can be used for the challenging scenario in which reconstructive and cosmetic goals are equally important.

Level of evidence: Level V, therapeutic study.
\end{abstract}

Keywords Microsurgery $\cdot$ Breast reconstruction $\cdot$ Stacked flaps $\cdot$ Free tissue transfer

\section{Introduction}

Breast reconstruction aims to restore shape and volume for patients that have lost their breast as part of their cancer treatment. Free tissue transfer has been demonstrated to provide better patient satisfaction compared to implant-based reconstructions [1]. Moreover, microsurgical reconstruction offers an alternative that allows patients being discharged sooner [2], with less need of revision surgery, resulting in an overall financial benefit for health systems [3].

The principle behind the use of free flaps for autologous breast reconstruction is the transfer of distant tissue to address two main issues: restoration of the breast skin envelope and providing sufficient volume inside of this envelope. The deep inferior epigastric perforator (DIEP) has demonstrated to be a reliable flap option

Juan Enrique Berner

juan.berner@nhs.net

1 Queen Victoria Hospital NHS Foundation Trust, Holtye Road, East Grinstead, UK

2 Kellogg College, University of Oxford, Oxford, UK providing both a large skin area and adequate filling in the majority of patients, becoming most microsurgeons' first choice [4]. However, it is not uncommon that for thin patients, abdominalbased free flaps are not able to provide sufficient volume to match the contralateral side and obtain a satisfactory aesthetic result.

This issue can be addressed in two ways: either by increasing the amount of transferred tissue, by stacking flaps in the reconstructed side $[5,6]$, or by reducing the size of the contralateral breast, at the same time or later. Nevertheless, when two flaps are not enough and the patient declines a volume reduction on the other side, achieving a satisfactory reconstruction can become a real challenge. The aim of this article is to present a case in which a bi-pedicled DIEP flap along with a TUG flap was used to reconstruct the breast for a slim patient in this clinical scenario.

\section{Case report}

A 49-year-old patient was referred to our unit for a delayed breast reconstruction. Three years previously, she had a rightside mastectomy for breast cancer followed by adjuvant radiotherapy and chemotherapy. She had no other comorbidities, had never smoked and had a body mass index (BMI) of 24 . On examination, she presented with a mildly ptotic $\mathrm{C}$ cup left breast and a well-healed mastectomy scar on the right side 
Fig. 1 Preoperative photographs

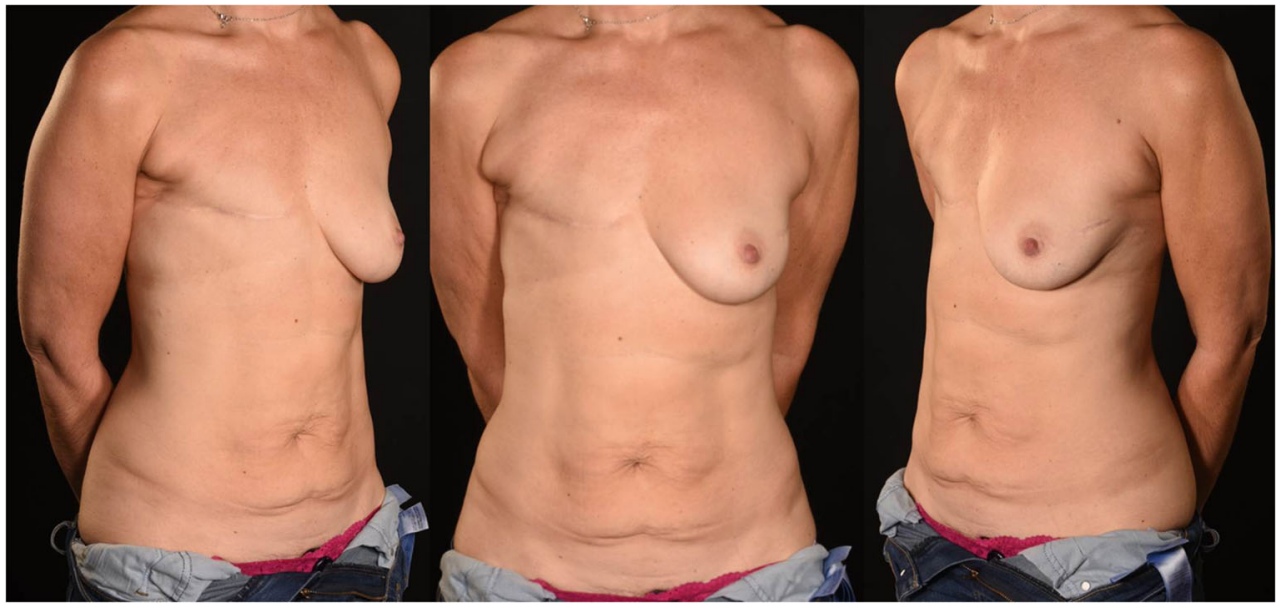

(Fig. 1). Her abdomen presented sufficient skin laxity due to previous pregnancies but lacked subcutaneous tissue volume. It had a skin pinch of $1.5 \mathrm{~cm}$. Her thighs were more generous in terms of volume but lacked the skin required for a symmetrical breast shape, even if bilateral TUG flaps were used.

A variety of autologous and implant-based reconstructions were offered to this patient, along with the possibility of symmetrising surgery after her reconstruction. She insisted in having an autologous reconstruction that could match the other side as much as possible, in just one sitting. In order to achieve these demands, a bi-pedicled DIEP flap was planned to provide enough skin for the reconstructed breast mound and maximum volume, combined with a buried TUG flap, to deliver enough volume and projection in the lower pole of the breast.

After having a preoperative anaesthetic preassessment, the patient was admitted the same day of her surgery. For her operation, a two surgical team approach was used: the consultant raised the bi-pedicled DIEP flap while his registrar prepared the internal mammary vessels.

For the preparation of the recipient site, the 3rd costal cartilage with the intercostal muscles above and below it, were excised while carefully preserving the second intercostal space perforators arising from the internal mammary system. The internal mammary vessels were exposed and prepared with the microscope between the second and fourth costal cartilages. Once the bi-pedicled DIEP was fully dissected and detached from its source, the internal mammary vessels were clamped proximally and distally and divided in the middle of their prepared lengths. While the primary deep inferior epigastric pedicle, supplying the medial breast reconstruction skin, was anastomosed to the proximal end of internal mammary vessels, the secondary pedicle was anastomosed to the 2 nd intercostal perforators, to perfuse the lateral skin. To tackle the 1:3 size mismatch between the secondary deep inferior epigastric artery (DIEA) and the recipient IMA perforator, a 1-mm

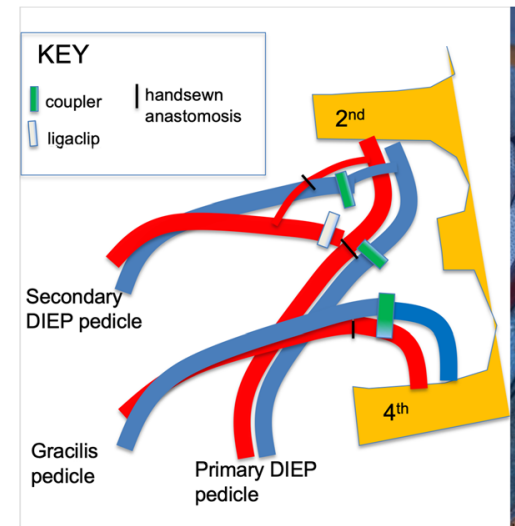

Fig. 2 Diagram and photograph showing how microanastomosis were performed with the primary DIEP pedicle being anastomosed anterograde to the internal mammary vessels, the secondary DIEP

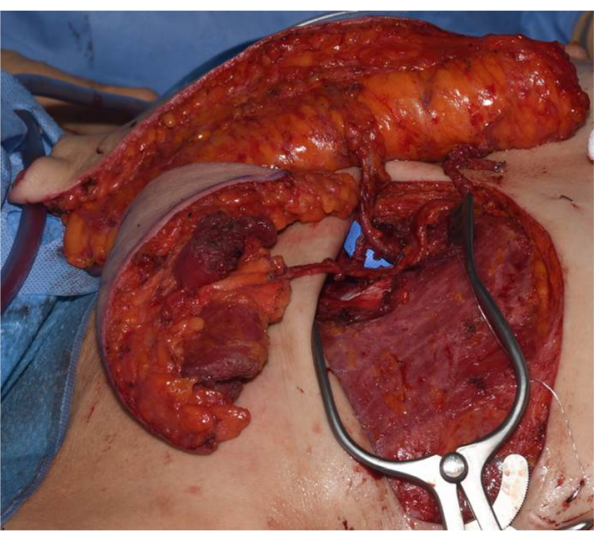

pedicle on to the 3 rd intercostal perforators of the internal mammary vessels and the TUG flap retrograde on the internal mammary vessels 
Fig. 3 Burying of the TUG under the bi-pedicled DIEP flap.

Projection and volume were assessed by breaking the operative table to sit the patient up

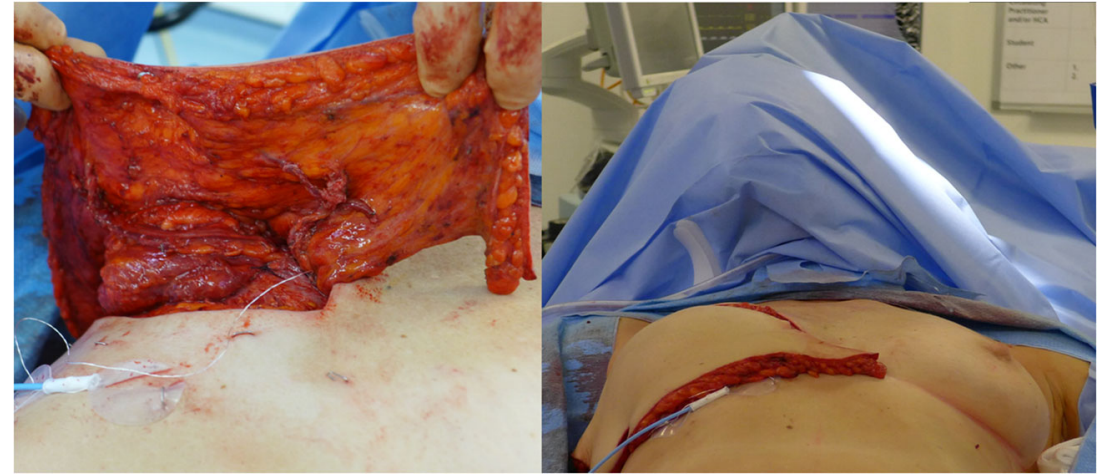

diameter side branch of the DIEA was used near its origin. This strategy allowed preserving the distal internal mammary artery and vein to receive the third pedicle for the TUG flap in a retrograde fashion.

Once the bi-pedicled DIEP had been re-perfused, it was provisionally inset into the defect. Adequate skin cover was achieved; however, as suspected, it lacked filling and projection to match the contralateral site in its lower pole. A contralateral TUG flap, which the patient was counselled would be necessary and had been consented for, was therefore raised. It was de-epithelialised and anastomosed to the distal end of the internal mammary vessels (Fig. 2). An implantable doppler was installed to monitor the TUG flap vein and the TUG flap was secured to the chest wall with absorbable stitches under the bi-pedicled DIEP flap (Fig. 3).

The total operative time was $8 \mathrm{~h}$ and postoperative recovery was uneventful. This patient had her urine catheter, abdominal and left breast drain removed the following day after surgery and was discharged a day later. Four-month postoperative photographs are shown in Fig. 4.

\section{Discussion}

Autologous breast reconstruction is a procedure that can restore the lost anatomy for patients that have suffered from breast cancer. It has not only a physical and aesthetic benefit, but also a psychological one, with high satisfaction rates.

It is our philosophy that a breast reconstruction should be, first of all, safe for our patients. This issue is addressed from the very beginning with a rigorous preoperative assessment, optimization and planning and continues in the peri-operative period: with strict deep vein thrombosis prophylaxis, intraoperative physiotherapy and early mobilization. On top of this, we maintain a low flap loss rate, by delivering a consultant-led service while training the next generations of microsurgeons [7]. This has allowed us to allow our trainees to perform just over $50 \%$ of our microsurgical breast reconstruction procedures whilst keeping our flap loss rate to $0.5 \%$ in our last 1799 free flap breast reconstructions. Finally, our third priority is to provide the best possible cosmetic reconstruction for our patients, as shown in this case report.

Fig. 4 Postoperative photographs 4 months after surgery

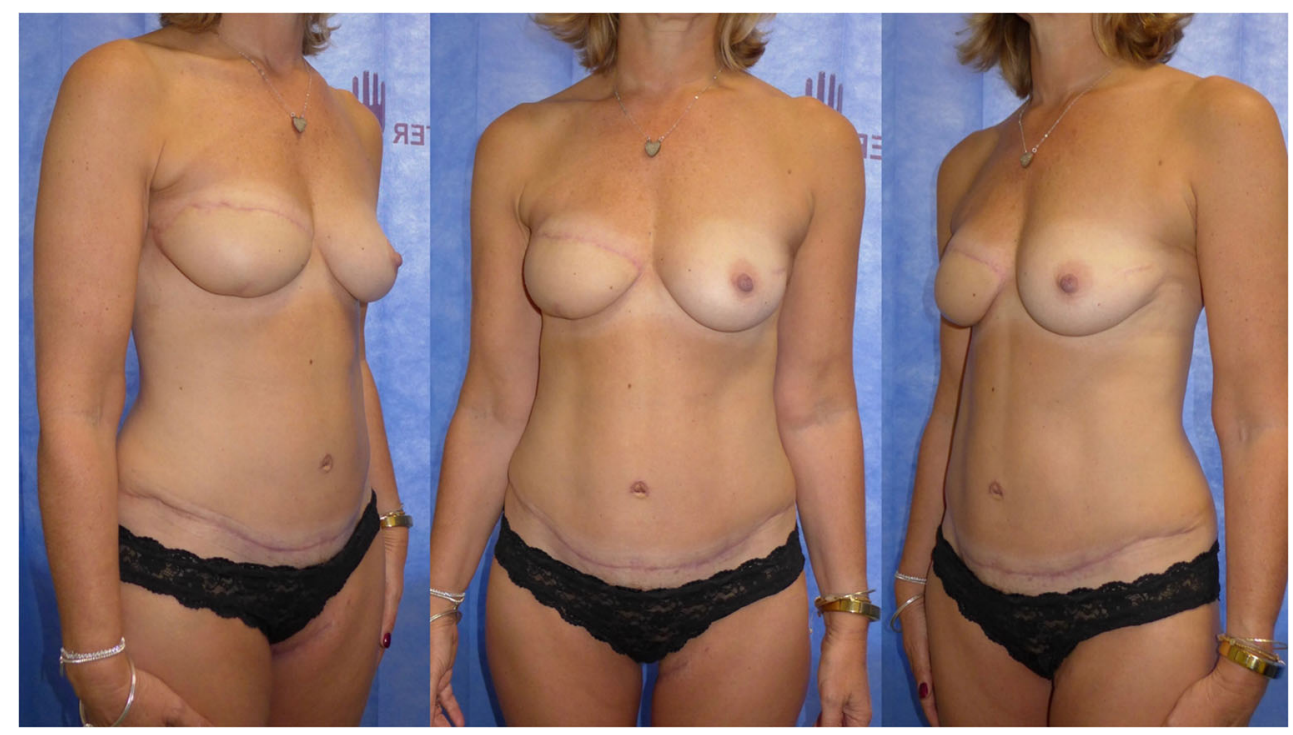


This case illustrates a particular reconstructive strategy for this specific patient, which to our knowledge has not been previously described in the literature. A meticulous dissection of the internal mammary vessels and preservation of its perforators allowed three pedicles to be used for one breast reconstruction. In this way, the potential morbidity that may be associated with the exposure of a second recipient site was avoided. Vessel size mismatch can be a problem in this situation, as it was encountered when performing the anastomosis of the secondary DIEA with the IMA perforator. This 1:3 discrepancy in vessel diameter was resolved by using a smaller similar sized side-branch of the DIEA rather than the main vessel.

Though it is not uncommon to need two free flaps to reconstruct one breast, this is the first time that we have had to anastomose three pedicles for one breast reconstruction. Here, we share our limited experience that resulted in a safe and cosmetically pleasant reconstruction for this patient.

\section{Compliance with ethical standards}

Patient's consent The patient involved in this manuscript signed a consent form allowing us to include her photographs in this manuscript.

Conflict of interest The authors Juan Enrique Berner, Ashish Magdum and Adam Blackburn declare that they have no conflicts of interest.

Open Access This article is licensed under a Creative Commons Attribution 4.0 International License, which permits use, sharing, adaptation, distribution and reproduction in any medium or format, as long as you give appropriate credit to the original author(s) and the source, provide a link to the Creative Commons licence, and indicate if changes were made. The images or other third party material in this article are included in the article's Creative Commons licence, unless indicated otherwise in a credit line to the material. If material is not included in the article's Creative Commons licence and your intended use is not permitted by statutory regulation or exceeds the permitted use, you will need to obtain permission directly from the copyright holder. To view a copy of this licence, visit http://creativecommons.org/licenses/by/4.0/.

\section{References}

1. Hu ES, Pusic AL, Waljee JF, Kuhn L, Hawley ST, Wilkins E, Alderman AK (2009) Patient-reported aesthetic satisfaction with breast reconstruction during the long-term survivorship Perio. Plast Reconstr Surg 124:1-8

2. Sindali K, Harries V, Borges A et al (2019) Improved patient outcomes using the enhanced recovery pathway in breast microsurgical reconstruction: a UK experience. JPRAS Open 19:24-34

3. Lagares-Borrego A, Gacto-Sanchez P, Infante-Cossio P et al (2016) A comparison of long-term cost and clinical outcomes between the two-stage sequence expander/prosthesis and autologous deep inferior epigastric flap methods for breast reconstruction in a public hospital. J Plast Reconstr Aesthetic Surg 69:196-205

4. Dibbs R, Trost J, DeGregorio V, Izaddoost S (2019) Free tissue breast reconstruction. Semin Plast Surg 33:059-066

5. Patel NG, Rozen WM, Chow WTH, Chowdhry M, Fitzgerald O'Connor E, Sharma H, Griffiths M, Ramakrishnan VV (2016) Stacked and bipedicled abdominal free flaps for breast reconstruction: considerations for shaping. Gland Surg 5:115-121

6. Rozen WM, Patel NG, Craggs BS, Ramakrishnan VV (2016) Fourflap breast reconstruction with bilateral stacked flaps. Plast Reconstr Surg 137:492e-493e

7. Moller L, Berner JE, Dheansa B The reconstructive journey: description of the breast reconstruction pathway in a high-volume UK-based microsurgical Centre. J Plast Reconstr Aesthetic Surg

Publisher's note Springer Nature remains neutral with regard to jurisdictional claims in published maps and institutional affiliations. 